\title{
Effects on gastric mucosa induced by dental bleaching - an experimental study with 6\% hydrogen peroxide in rats
}

\author{
Anabela Baptista PAULA ${ }^{1}$, Maria Isabel DIAS ${ }^{2}$, Manuel Marques FERREIRA ${ }^{1}$, Teresa CARRILHO', Carlos Miguel \\ MARTO', João CASALTA', António Silvério CABRITA' ${ }^{1}$, Eunice CARRILHO' ${ }^{1}$
}

1- Universidade de Coimbra, Escola de Medicina, Coimbra, Portugal.
2- Universidade de Trás-Os-Montes e Alto Douro, Escola de Ciências Agrárias e Veterinárias, Vila Real, Portugal.

Corresponding address: Anabela Baptista Pereira Paula - Av. Bissaya Barreto, 3000-075 - Coimbra - Portugal - Phone: +351 934262687 - Fax: +351 239402910 - e-mail: anabelabppaula@sapo.pt / anabelabppaula@gmail.com

Submitted: May 25, 2015 - Modification: August 12, 2015 - Accepted: August 26, 2015

\section{ABSTRACT}

\begin{abstract}
The he value of aesthetic dentistry has precipitated several developments in the investigation of dental materials related to this field. The free marketing of these products is a problem and it is subject to various interpretations regarding its legality. There are several techniques for tooth whitening, the most used one being the external bleaching. It is the later version of such technique that poses the greatest danger of ingesting the product. The present study analysed the systemic effect of these products when they are swallowed. Objective: This experimental study aimed to observe the effects of a tooth whitening product, whose active agent is $6 \%$ hydrogen peroxide, on the gastric mucosa of healthy and non-tumour gastric pathology animals. Material and Methods: Fifty Wistar-Han rats were used and then distributed into 5 groups, one for control and four test groups in which the bleaching product was administered in animals with and without non-tumour gastric pathology (induced by the administration of 1 sample of 50\% ethanol and $5 \%$ of drinking water during 6 days) at different times of study by gavage. There was a decrease in body weight in animals of groups handled during the study period, which was most pronounced in IV and VA groups. Changes in spleen weight relative to body weight revealed no statistically significant changes. An analysis of the frequency was performed on the results of macroscopic observation of the gastric mucosa. Results: The gastric mucosa revealed lesions in all manipulated groups, being more frequent in groups III and IV. It appears that there is a synergism when using hydrogen peroxide and $50 \%$ ethanol in the same group. Conclusion: Therefore, it seems that there are some signs of toxicity 3 to 4 days after administration of $6 \%$ hydrogen peroxide. The prescription of these therapies must be controlled by the clinician and the risks must be minimized.
\end{abstract}

Keywords: Ambulatory monitoring. Bleaching agents. Gastritis. Hydrogen peroxide. Tooth bleaching. Toxicity.

\section{NTRODUCTI ON}

Dental bleaching carried out with an unstable chemical oxidant agent has been, for a long time, a conservative alternative to the recovery of vital aesthetic and chromatic aberrations in teeth with endodontic treatment. However, all bleaching therapies known and practised today have several limitations and complications that can and must be recognised, so that they can be avoided ${ }^{6,13,16}$.

The definition of the aetiology and its diagnosis is important to establish an appropriate treatment plan, evaluating the absolute necessity of intervention or, on the other hand, its simple resolution with prophylactic procedures. The technique of home external bleaching is extremely popular considering it is practical, simple, and of low cost ${ }^{6,11}$. These characteristics have turned the technique easily marketable, being now available in free-sale kits for whitening treatments, which include whitening products and universal trays from pharmacies or over the internet ${ }^{9}$. Such free-sale kits for tooth 
whitening treatments may have a whitening product with two kinds of active ingredient, or hydrogen peroxide or carbamide peroxide, at different concentrations depending on the brand ${ }^{6,16}$.

Changes in oral tissues can occur if an excessive amount of bleach is used, or if the set protocol is not carried out $4,17,18,24$. The use of hydrogen peroxide generally involves a greater risk to soft tissues when compared to carbamide peroxide. It is caustic and can cause chemical burns and gingival necrosis if the adequate protection of these tissues is not carried out $14,20,25,27$. The bleaching treatments performed with Over-The-Counter (OTC) products were due to the use of universal trays with poor adaptation to dental arches, which may increase the risk of gingival erosions and ulcers in the oral mucosa, especially when there is severe dental misalignment $7,10,17,28,22$.

The various bleaching techniques have different degrees of risk and side effects for patients depending on the techniques used and on the regularity of controls made by the dentist ${ }^{21}$. There are also different concentrations of active ingredients used, particularly with higher hydrogen peroxide concentrations ${ }^{18}$. The actual effect of these higher concentrations on oral, oesophageal, gastric, and intestinal mucosa has not been thoroughly studied yet. When performing this therapy, it is critical to have the clinical history of the patient, since the presence of any pathology of the digestive system may be considered a contraindication, representing an increase in the risk of worsening this condition regardless of the amount of product swallowed (at the very least, it could aggravate the clinical condition of such patients) ${ }^{17,22}$. This clinical situation has not been studied and is not referenced in studies of this therapy. Given this gap in the research of whitening products, it seemed important to start the testing in animals that have had gastrointestinal pathology induced.

In this experimental work, $6 \%$ of hydrogen peroxide was used, since this product is less studied than carbamide peroxide. In most studies, the hydrogen peroxide has side-effects, considering that, until recently, it was only used in clinical medical practice and, therefore, it was always manipulated by a dentist. Now with the existence of the new home formulae that can be used by patients, there is a higher risk of potential side effects in patients ${ }^{12,23}$.

This experimental study intended to observe the effects of a tooth whitening product, whose active agent is $6 \%$ hydrogen peroxide, on the gastric mucosa of healthy and with no gastric tumour pathology animals.

\section{MATERI AL AND METHODS}

\section{Animals}

This experimental study was evaluated by an Advisory Committee for the Protection of Animals used for Experimental and/or other Scientific Purposes, (paragraph b of number 49 of the Decree $1005 / 92$ of 23 October), having been authorized for its realization. Similarly, authorization was also given by the General Direction of Veterinary Services, Direction of Health Defence Services, Welfare and Animal Food.

During the experimental period, the animals were kept in standard laboratory conditions, according to the legislation in force (Decree $113 / 2013$ of 7 August). All animals were observed daily. Throughout the time of the experiment, records of animal weight were made weekly and daily records of any visible behavioural change. All animals were subjected to normal conditions of maintenance and nutrition, with an ambient temperature of $22^{\circ} \mathrm{C}$ and cycles of $12 \mathrm{~h} / 12 \mathrm{~h}$ light/ dark. All animals were housed in cages appropriate to their species (2-3 animals per cage). The diet consisted of a complete ration of granules, standard for laboratory rodents and acidified water ad libitum in a system subject to the same environmental conditions.

\section{Experimental design}

For this study, we used 50 rats of the strain Wistar-Han of 8 weeks of age, with about 250 grams in weight. In week 1 , all animals were quarantined. In periods II and III, which took place in the $2^{\text {nd }}$ and $3^{\text {rd }}$ weeks, the animals were subjected to different test protocols, and divided into 5 groups with 10 animals each. The group I was the negative control, in which the animals were not manipulated, while the groups II and $\mathrm{V}$ were the positive control groups in which the animals were subjected to the administration of a bleaching agent (group II)

\begin{tabular}{|l|c|c|c|}
\hline \multicolumn{1}{|c|}{$\begin{array}{c}\text { STUDY } \\
\text { GROUPS }\end{array}$} & \multicolumn{3}{|c|}{ STUDY TIME } \\
\hline & $\mathbf{1}^{\text {st }}$ week & $\mathbf{2}^{\text {nd }}$ week & 3 $^{\text {rd }}$ week \\
\hline I Group & Q & & \\
\hline II Group - A & Q & P & \\
\hline II Group - B & Q & & P \\
\hline III Group & Q & G & P \\
\hline IV Group & Q & P & G \\
\hline V Group - A & Q & G & \\
\hline V Group - B & Q & & G \\
\hline
\end{tabular}

Figure 1- Experimental procedure performed in the various groups. ( $Q$ - quarantine, $P$ - hydrogen peroxide administration; G - non-tumoral gastric pathology induced) 
and to an non-tumour gastric pathology induction protocol by administering a chemical compound (group $\mathrm{V}$ ). These groups were divided into two subgroups to control all other test groups. In group III, which is the test group that expresses the goal of the study, the animals were subjected to a non-tumour gastric pathology induction protocol by administering a chemical compound in the $2^{\text {nd }}$ week and the administration of a bleaching agent in the $3^{\text {rd }}$ week. In the group IV the administration were exactly the opposite of the previous group. All products were administered to the animals by gavage. Figure 1 summarizes the experimental procedure performed in the various groups.

\section{Chemicals}

For the induction of non-tumour gastric pathology, a single administration of $1 \mathrm{ml} / \mathrm{kg}$ dose of $50 \%$ ethanol was performed by gavage; after 6 more subsequent days it was performed with $5 \%$ ethanol in drinking water. As the bleaching agent was used in a commercial preparation of hydrogen peroxide 6\% (Colgate Oral ${ }^{\mathrm{TM}}$ Colgate Visible White ${ }^{\circledR}$ Pharmaceuticals Inc, New York, USA) administered in a dose of $1 \mathrm{~g} / \mathrm{Kg}$ during for 7 days, by gavage.

During the first 3 hours after the administration of the bleaching product, the animals' diet was restricted. To comply with the experimental protocol above, the bleaching product doses were administered differently according to the weight of each animal, and were adjusted every 3 days, according to new animal weight.

\section{Tissue preparation}

By the end of the $3^{\text {rd }}$ week, all animals were euthanized. After confirming the absence of vital signs, all macroscopic changes in the external appearance of each animal were observed and recorded. After dissection, each animal was observed in detail and an exhaustive study was made with the intention of identifying any macroscopic lesions in organs (colour, consistency, inspection, and palpation). The spleen was taken, weighed and measured in three dimensions (length, height, and width). Samples were taken from the stomach and fixed in $10 \%$ of neutral buffered formaldehyde from 24 to 36 hours depending on the fragment's thickness. Samples were prepared for histological study. After fixation, they were processed according to the guidance that had been programmed, leaving the mucosa plane perpendicular to the cutting plane. The processing was carried out in the conventional manner, after dehydration in increasing concentrations of ethanol and subsequently embedded in paraffin. Different cuts of $5 \mu \mathrm{m}$ thick were made, followed by the colouring.

All data are presented as Mean \pm Standard
Error (SE). The influence of time and treatment parameters in body and spleen weight at the time of the euthanasia were evaluated by Analysis of Variance (ANOVA) and an student $t$ test was conducted in the presence of significant differences in multiple comparisons of pairs of means. The realization of contrasts was carried out between groups subjected to different treatments. Statistical analysis was performed using the statistical software program JMP (JMP Version 7, SAS Institute, Inc., NC, USA). Differences were considered significant at a probability of $95 \%(p<0.05)$.

The evolution of animal weights in percentage was analyzed using the $t$ test for paired samples to a 0.05 significance level, and the significance of differences between groups was assessed by Kruskal-Wallis test.

The results analysis was performed by macroscopic examination and histological observation of several changes. Gastric mucosa was examined macroscopically and each lesion was graded and scored based on its incidence and severity according to an arbitrary grading system. The grade of severity was attributed differently in each parameter: hemorrhagic areas (rated 0 to 5); loss of mucosal folds (rated 0 to 5 ); necrotic areas/ ulcers (rated from 0 to 3 ); perforation $(0,10)$. The Ulcer Index (UI) for each stomach was the sum of scores of all lesions. The UI for each experimental group was reported as median (minimummaximum). The significance of differences between groups was assessed by the Kruskal-Wallis test. $\mathrm{P}<0.05$ versus control was taken as significant.

For histological analysis, the staining routine performed on each of the samples was the Haematoxylin-Eosin (HE). The microscopic observation of these histological sections was performed by light microscopy by an independent observer.

\section{RESULTS}

During the study period, most animals showed a healthy appearance with motor activity and normal breathing. However, few animals of all groups (except control negative group) presented occasionally respiratory symptoms, including wheezing, without specific patterning. Hair loss and its rough appearance was also one of the characteristics common in some animals, once again without there being any specific standardization. During the study period, two animals died: one from the VA group by the $9^{\text {th }}$ day of experimental work, one day after $50 \%$ ethanol was administered; and another from the IIIB group by the day 18 , two days after starting the administration of hydrogen peroxide. In almost all groups there was an increase in weight, by comparing the beginning and end of 
the experimental work. Statistical analysis of weight data was translated in Table 1.

The negative control group had a constant weight increase in animals through the entire duration of the experimental work. The evolution of the mean weight gains of all other groups are compared with this group, as show in Figure 2.

The analysis of the figure shows group II did not gained weight constantly. The subgroup B, early in the $2^{\text {nd }}$ week of study, has gained weight faster

Table 1- Statistical results with mean values $\pm S E$ of the animal weights of the various experimental groups over study time and paired mean comparison $(p<0.0001)$. The letters A, B and C correspond to significant differences between the values of the same column between groups. Same letters mean no significant differences between values of the same column

\begin{tabular}{|c|c|c|c|c|c|}
\hline \multirow{2}{*}{$\begin{array}{c}\text { Study Time } \\
\text { Day } 7\end{array}$} & \multirow{2}{*}{$\begin{array}{c}\text { Group } \\
\text { Gr I }\end{array}$} & \multirow{2}{*}{$\begin{array}{l}\text { Least Sq Mean } \\
\qquad 351.4\end{array}$} & \multirow{2}{*}{$\begin{array}{c}\text { Std Error } \\
\pm 5.46\end{array}$} & \multicolumn{2}{|c|}{$\begin{array}{c}\text { Paired mean } \\
\text { comparison } \\
\text { (Student's } T \text { ) } \\
\quad P<0.0001\end{array}$} \\
\hline & & & & & \\
\hline & Gr II-A & 298.4 & \pm 7.72 & & \\
\hline & Gr II-B & 285.8 & \pm 7.72 & & \\
\hline & Gr III & 287.2 & \pm 5.75 & & \\
\hline & Gr IV & 288.5 & \pm 5.46 & & \\
\hline & Gr V-A & 295.4 & \pm 7.72 & & \\
\hline & Gr V-B & 296.5 & \pm 8.63 & & \\
\hline \multirow[t]{7}{*}{ Day 10} & Gr I & 353.85 & \pm 5.54 & & \\
\hline & Gr II-A & 313.0 & \pm 7.84 & B & $C$ \\
\hline & Gr II-B & 314.2 & \pm 7.84 & & \\
\hline & Gr III & 293.4 & \pm 5.84 & & \\
\hline & Gr IV & 300.0 & \pm 5.54 & B & $C$ \\
\hline & Gr V-A & 299.64 & \pm 7.84 & B & $C$ \\
\hline & Gr V-B & 301.75 & \pm 8.76 & B & $C$ \\
\hline \multirow[t]{7}{*}{ Day 15} & Gr I & 365.4 & \pm 5.97 & & \\
\hline & Gr II-A & 322.0 & \pm 8.44 & & \\
\hline & Gr II-B & 319.8 & \pm 8.44 & & \\
\hline & Gr III & 296.77 & \pm 6.29 & & \\
\hline & Gr IV & 306.4 & \pm 5.97 & B & $C$ \\
\hline & Gr V-A & 311.0 & \pm 8.44 & B & $C$ \\
\hline & Gr V-B & 313.28 & \pm 9.44 & B & $C$ \\
\hline \multirow[t]{7}{*}{ Day 18} & Gr I & 375.19 & \pm 7.94 & & \\
\hline & Gr II-A & 329.8 & \pm 11.22 & & \\
\hline & Gr II-B & 319.2 & \pm 11.22 & B & $C$ \\
\hline & Gr III & 304.0 & \pm 8.37 & B & $C$ \\
\hline & Gr IV & 298.6 & \pm 7.94 & & \\
\hline & Gr V-A & 327.37 & \pm 11.22 & & \\
\hline & Gr V-B & 297.98 & \pm 12.55 & B & $C$ \\
\hline \multirow[t]{7}{*}{ Day 22} & Gr I & 381.36 & \pm 8.49 & & \\
\hline & Gr II-A & 337.44 & \pm 12.00 & & \\
\hline & Gr II-B & 322.96 & \pm 12.00 & B & $C$ \\
\hline & Gr III & 326.66 & \pm 8.95 & & \\
\hline & Gr IV & 299.62 & \pm 8.49 & & \\
\hline & Gr V-A & 342.85 & \pm 12.00 & & \\
\hline & Gr V-B & 310.05 & \pm 13.42 & B & C \\
\hline
\end{tabular}


than subgroup A. At the beginning of the $3^{\text {rd }}$ week, subgroup A described a curve similar to control group, while subgroup B remained with the same weight, only slightly increasing by the end of that week. Group III had a very slight increase in weight during the entire study, a considerable difference in the control group, only revealing a significant increase in the last three days of the study. In group IV, the weight increase was moderate in the first two weeks, reversing the slope of increase in the $3^{\text {rd }}$ week of the study with weight loss. In group $\mathrm{V}$, the VA subgroup had a constant weight increase, with a similar curve to the control group. However, the VB group had a similar trend to group IV considering weight, showing slight signs of weight recovery in the last three days of the study.

The evolution of animal weights in percentage was showed in Figure 3, which compares the fraction of weight change from the beginning to the end of the study. There are statistical significant differences between the groups: control, III, VA $(<0.0001)$, and IIB $(<0.05)$, when compared with the group that have the lowest weight gain (group IV).
The results of the spleen weight were compared with the weight of the respective animals in the different groups. Table 2 shows the statistical analysis for the percentage change of animal and spleen weight and the relationship between these two parameters for each group and subgroup. In Table 2, it can be seen that there are statistically significant differences, marked with different letters, between the experimental groups studied. Between the control group and the manipulated groups, there are some significant differences, particularly with groups VA, IIB and IV. Between manipulated groups there are statistically significant differences, but only between the group VB and groups III and IV. In groups with subgroups (group II and V), no statistically significant differences were found between subgroups $A$ and $B$.

In the groups in which only one type of substance was administered, as groups II and V, no statistically significant differences were found when compared with the control group that was observed. Concerning the groups that administered two different substances (bleaching product and $50 \%$ ethanol), as groups III and IV, only the group

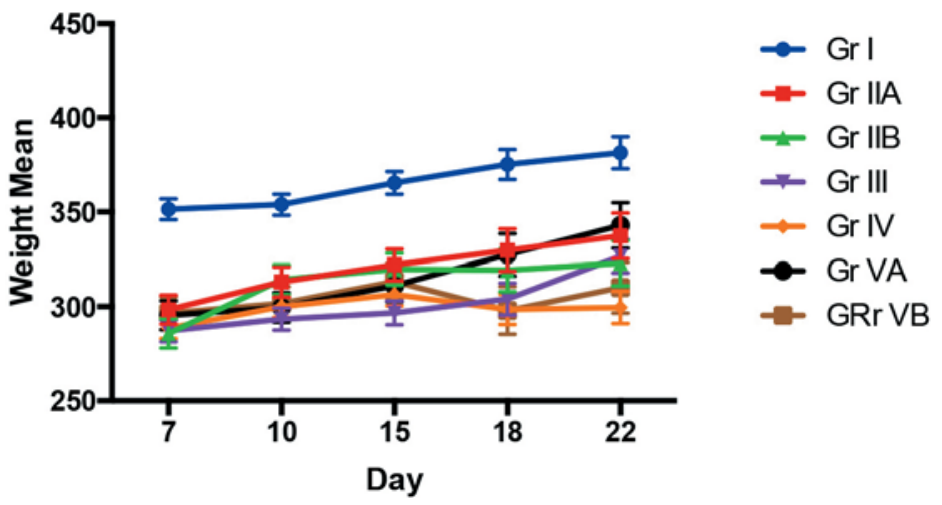

Figure 2- Results of the analysis of variance of animal weight in all experimental groups over study time. The results are presented as mean \pm standard error (SE) for all conditions tested

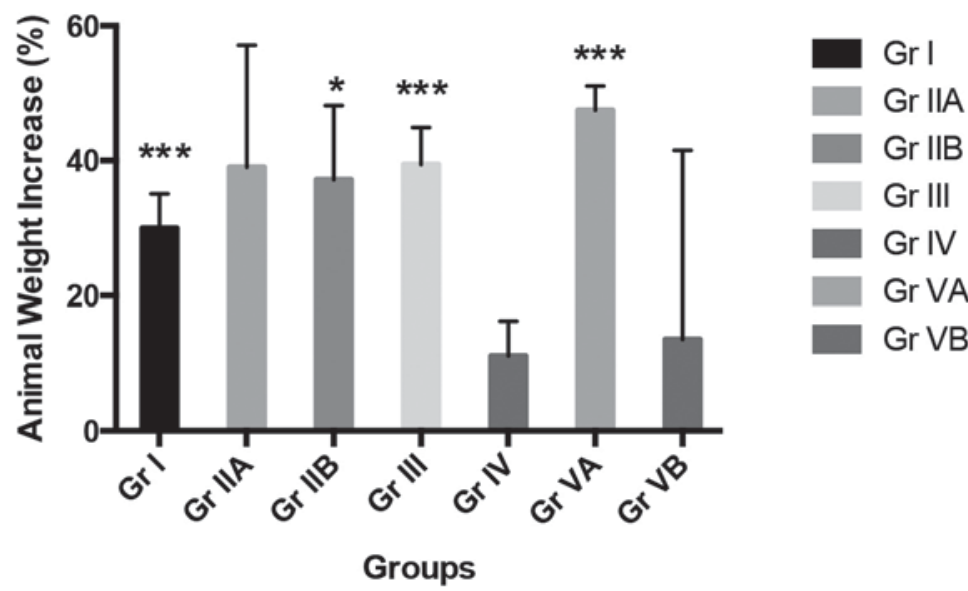

Figure 3- Results of the analysis of evolution of animal weights in percentage, which is the fraction of weight change from the beginning to the end of study. The results are presented as mean \pm standard error (SE) with a level of significance of $\left(^{*}\right)$ $<0.05 ;\left({ }^{* *}\right)<0.01 ;\left({ }^{* * *}\right)<0.001$ 
IV showed highly significant differences from the control group. The differences between the control groups and manipulated groups are all negative, which means spleen weight is always higher in the control group when compared to the other groups.

Figure 4 compares the variations of spleen weight relative to animal weight, based on the results of Table 2. Only the VA group shows statistically significant differences compared with the control group. However, the VA group also presents statistically significant differences compared with the two manipulated groups, groups VB and III.

Although we collected, analysed, and weighed various organs, some of them that required special attention during the autopsy. A more careful analysis of organs, particularly of lungs, spleen, oesophagus, and stomach was performed to determine the probability of systemic toxicity.

After the full cleaning of the gastric mucosa, lesions were observed in several different areas, thus classifying them according to the methodology of the macroscopic analysis. Statistical analysis was performed based on a frequency analysis, since the variables are discrete and not continuous. The microscopic observation for the histological analysis of the study group can be seen in Figure 5 .

The first parameter examined is related to the normal appearance of the mucosa, which was only found in the control group and in one animal of group VA and two animals of group VB, as shown in Figure 6.

For the analysis of Figure 7, we can observe that all manipulated groups have macroscopic areas corresponding to inflammation, which is more pronounced in groups II, IV, and VA. In group III, despite the fact that the highest frequency values corresponding to macroscopically inflammation areas are not present, over $50 \%$ of the animals

Table 2- Results of statistical analysis for comparison of animal and spleen weights. The "S1-S5" represents the various significances for each parameter analyzed. The letters $a, b$ and c correspond to significant differences between the values of the same column between groups. Same letters mean no significant differences between values of the same column

\begin{tabular}{ccccccccccc}
\hline Parameter & $\begin{array}{c}\text { Animal } \\
\text { weight (gr) }\end{array}$ & S1 & $\begin{array}{c}\text { Spleen } \\
\text { weight (gr) }\end{array}$ & $\begin{array}{c}\text { S2 } \\
\text { weight } \\
\text { variance (\%) }\end{array}$ & $\begin{array}{c}\text { Animal } \\
\text { variance (\%) }\end{array}$ & $\begin{array}{c}\text { Spleen } \\
\text { weight } \\
\text { vancight (\%) }\end{array}$ & $\begin{array}{c}\text { S4 } \\
\text { weight/animal } \\
\text { weight }\end{array}$ \\
\hline $\begin{array}{c}\text { I Group } \\
\text { (control) }\end{array}$ & 381.36 & $\mathrm{a}$ & 0.81 & $\mathrm{a}$ & -0.33 & $\mathrm{a}$ & -2.52 & $\mathrm{a}$ & 0.21 & $\mathrm{a}$ \\
II-A Group & 337.44 & $\mathrm{~b}$ & 0.69 & $\mathrm{abc}$ & -13.52 & $\mathrm{bc}$ & -19.12 & $\mathrm{abc}$ & 0.2 & $\mathrm{ab}$ \\
\hline II-B Group & 322.96 & $\mathrm{bc}$ & 0.67 & $\mathrm{bc}$ & -19.4 & $\mathrm{bcd}$ & -23.55 & $\mathrm{bc}$ & 0.21 & $\mathrm{ab}$ \\
\hline III Group & 326.66 & $\mathrm{~b}$ & 0.76 & $\mathrm{ab}$ & -16.99 & $\mathrm{bc}$ & -9.04 & $\mathrm{ab}$ & 0.23 & $\mathrm{a}$ \\
\hline IV Group & 299.62 & $\mathrm{c}$ & 0.61 & $\mathrm{c}$ & -27.94 & $\mathrm{~d}$ & -39 & $\mathrm{c}$ & 0.2 & $\mathrm{ab}$ \\
\hline V-A Group & 342.85 & $\mathrm{~b}$ & 0.65 & $\mathrm{bc}$ & -11.46 & $\mathrm{ab}$ & -25.92 & $\mathrm{bc}$ & 0.19 & $\mathrm{~b}$ \\
\hline V-B Group & 310.06 & $\mathrm{bc}$ & 0.72 & $\mathrm{abc}$ & -25.98 & $\mathrm{~cd}$ & -13.44 & $\mathrm{ab}$ & 0.24 & $\mathrm{a}$ \\
\hline
\end{tabular}

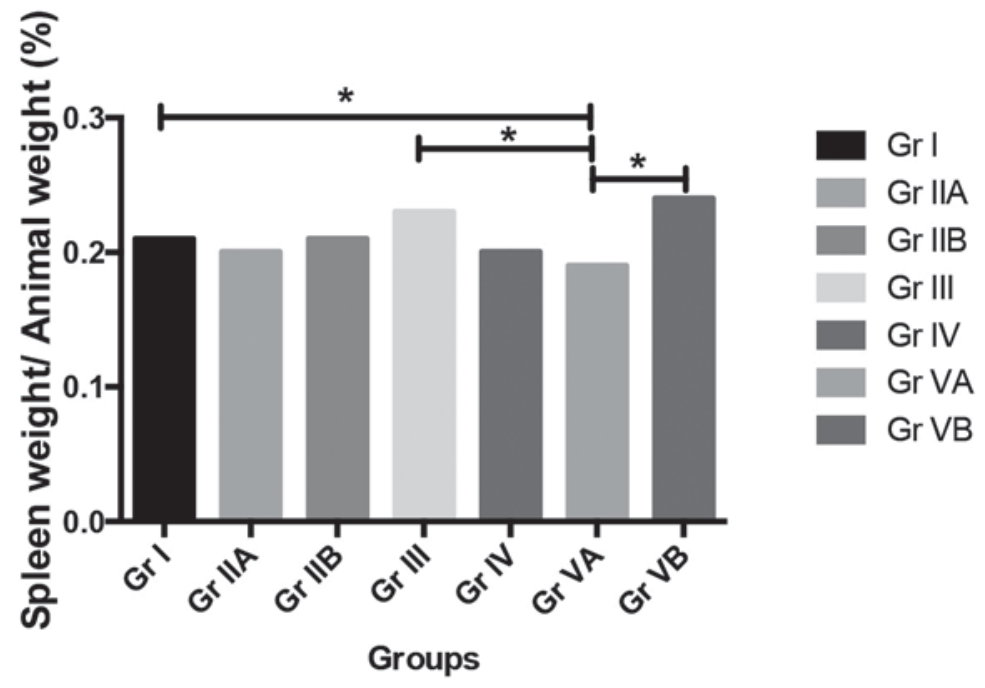

Figure 4- Results of the comparison as a percentage of the ratio of animal and spleen weight. The results are presented as mean with a level of significance of $\left(^{*}\right)<0.001$ 
of this group present high frequency values for this parameter. In group IV, both situations occur, presenting the highest frequency values and greater percentage of animals with gastric inflammation. The control group did not show any animals with macroscopic inflammation areas.

The erasing of the folds of the mucosa parameter does not show a generalized pattern, because a large percentage of animals of various manipulated groups have frequency zero of this parameter. Only in groups IIA, IV, and VA this feature is scored as the ones with most occurrence. However, in groups III, IV and VA, this parameter presents higher frequency (Figure 8).

All manipulated groups have macroscopic areas corresponding to bleeding. Groups III, IV, and VA have a large number of animals with this type of alteration, while the group VA has the highest frequency. Group II presents more than $50 \%$ of the animals with low frequencies of this parameter, which is still less pronounced in subgroup B. The control group shows no animals with this type of injury (Figure 9).

The frequency of macroscopic areas corresponding to necrosis or ulcer is low in all manipulated groups. This parameter is only

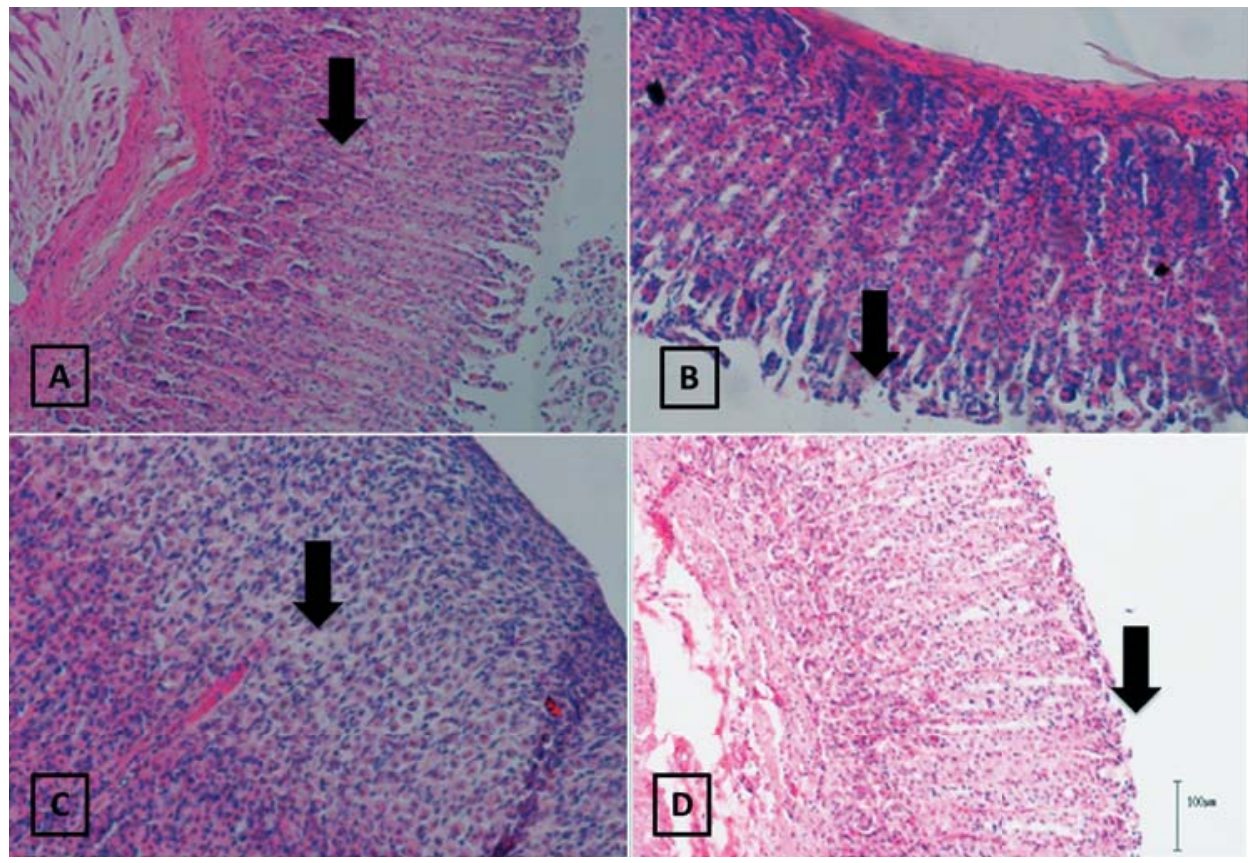

Figure 5- Histological observation. A- Group II, mucosal changes with foci of necrosis and sloughing can be observed; B- Group III, loss of the surface layer of the mucosal epithelium can be observed; C- Group IV, the presence of inflammatory infiltrate and edema may be observed; D- Group V, loss of superficial epithelial layer of the mucosa may be observed
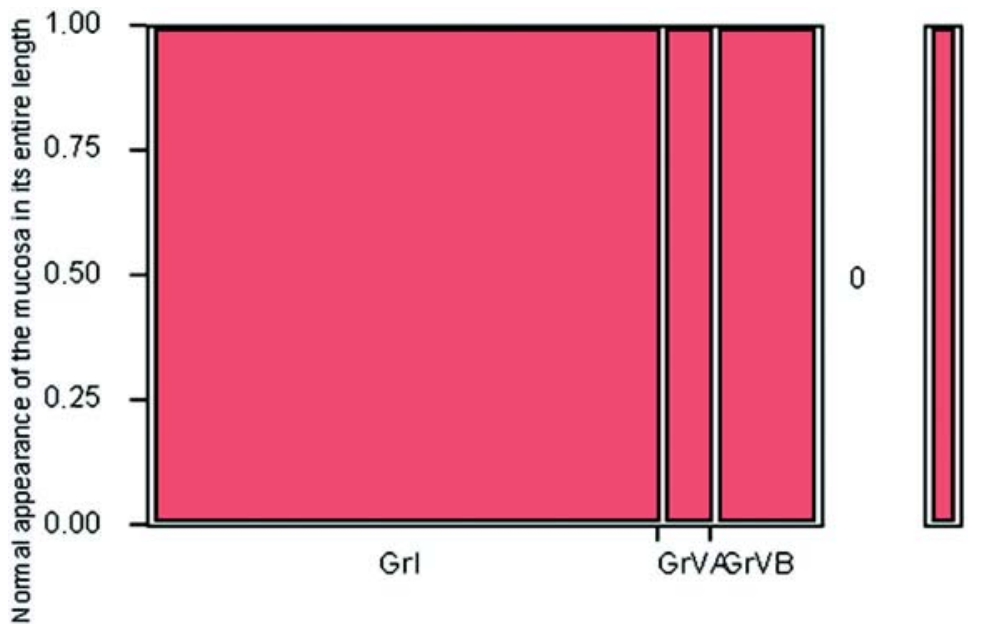

Figure 6- Macroscopic observation of the gastric mucosa in relation to parameter - Normal appearance of the mucosa in its entire length 


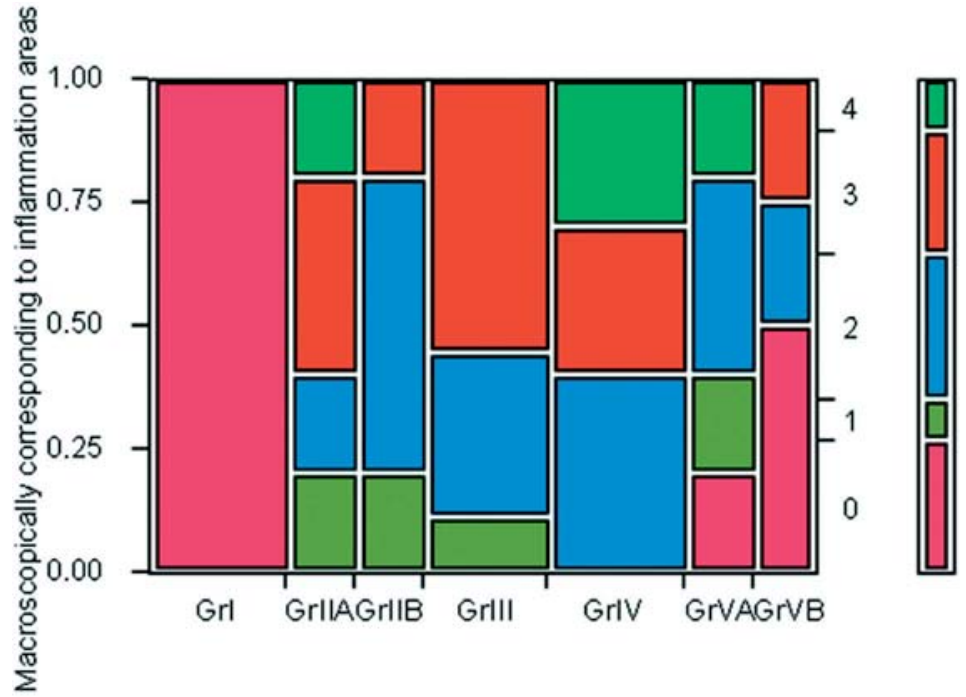

Figure 7- Macroscopic observation of the gastric mucosa in relation to parameter - Macroscopically corresponding to inflammation areas
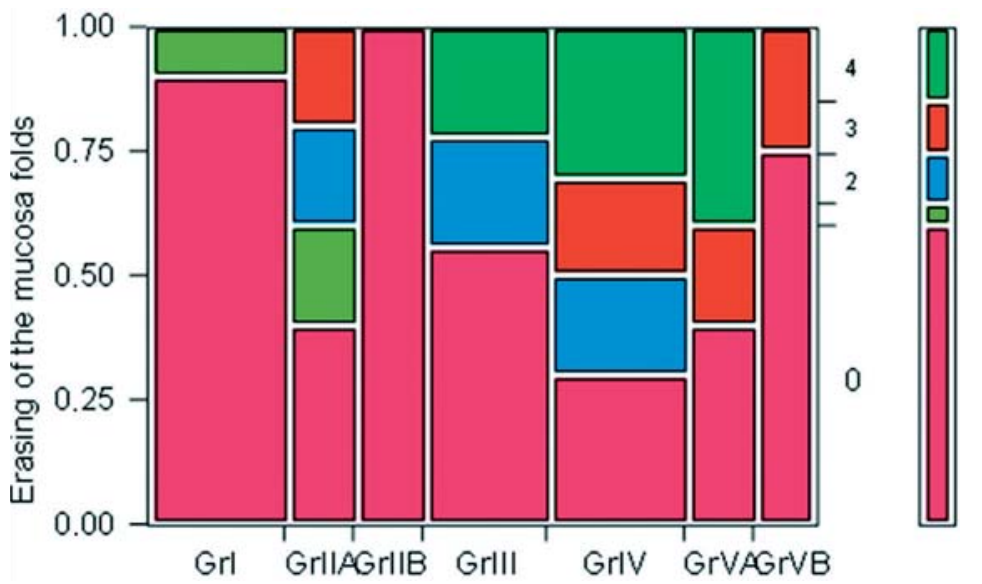

Figure 8- Macroscopic observation of the gastric mucosa in relation to parameter - Erasing of the mucosa folds

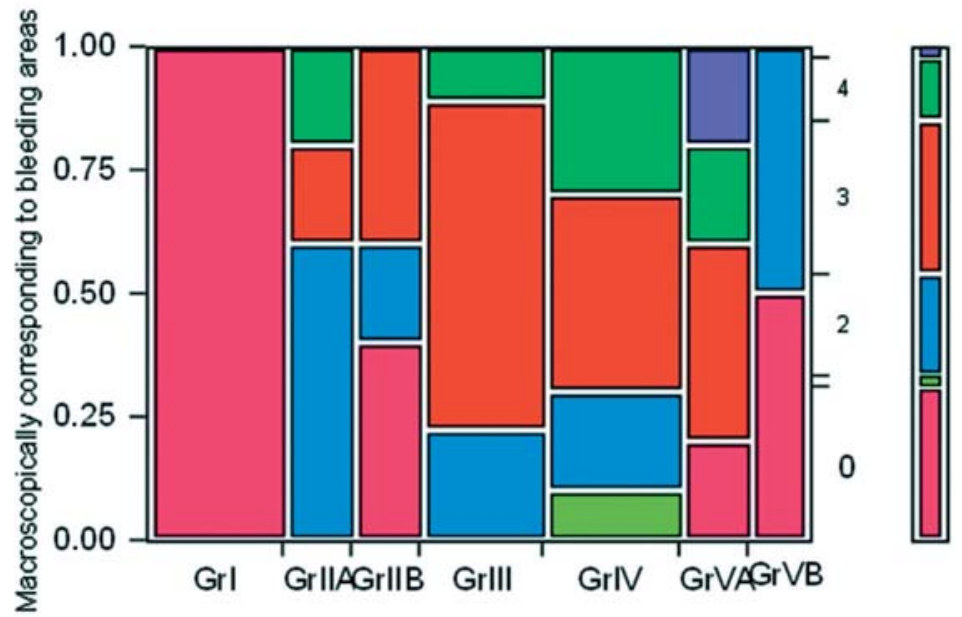

Figure 9- Macroscopic observation of the gastric mucosa in relation to parameter - Macroscopically corresponding to bleeding areas 


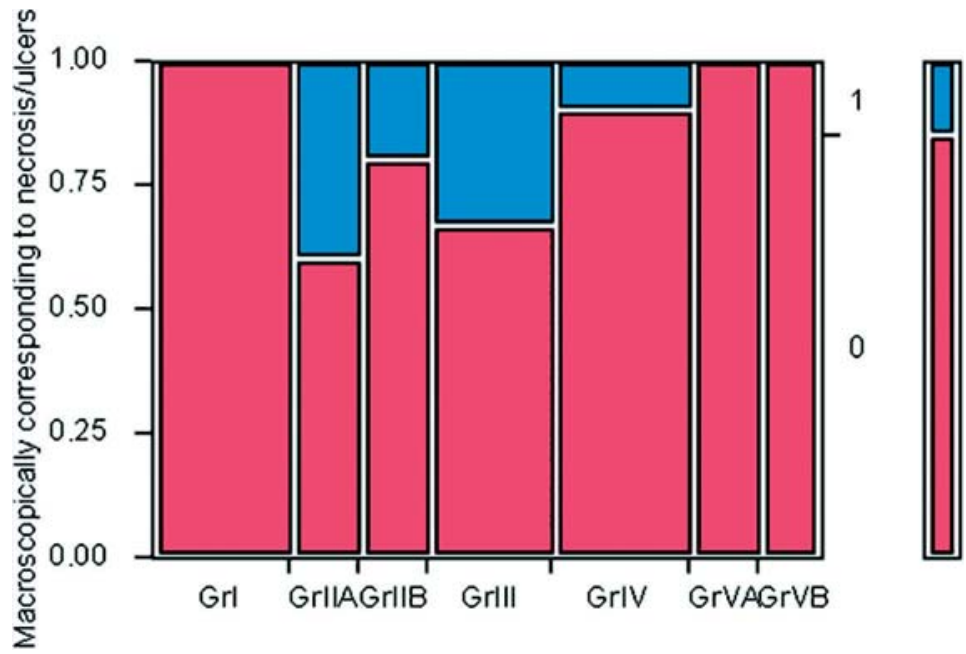

Figure 10- Macroscopic observation of the gastric mucosa in relation to parameter - Macroscopically corresponding to necrosis/ulcers

evident at a low frequency in group II (subgroup A and B), and in groups III and IV. Among these, the groups with the largest number of animals with this type of injury are the groups IIA and III. Group IV shows a very low number of animals with this parameter positive. Groups I, control, and V show no animal with this type of injury (Figure 10).

The inflammation and the bleeding parameters showed statistical significant differences between some groups. In the inflammation parameter, there are significant differences between the control group and the groups IIA (0.015), III (0.003), and IV $(<0.001)$. In the bleeding parameter, there are significant differences between the control group and the groups III (0.002), IV (0.001) and VA (0.011).

\section{SCUSSI ON}

In this experimental work, a therapy study in an animal model was chosen, since this type of testing can be performed to predict the biocompatibility of a particular product. These tests are much more reliable because they mimic better the clinical use of the products tested, including time, location, and application techniques. The rat model was chosen as described in several studies in the literature regarding the induction of gastric pathology and biocompatibility evaluation of various products in animal models ${ }^{1,4,5,6,26,28}$. To reduce the risk of developing gastric pathologies associated with old animals, subjects of 8 weeks old were chosen ${ }^{2}$.

The administration of $50 \%$ ethanol, bleaching product, hydrogen peroxide $6 \%$ was performed by gavage to ease the manipulation that allows this methodology.

A large number of studies on non-tumour induction of gastric pathologies use this method of administration ${ }^{2-5,15}$. The ease of handling and of the certification of the receipt of the product at the desired location without loss of the administered dose are considered reasons for the choice. With regard to the bleaching product, using it in a similar way to clinical practice was not possible with these animals. The maintenance of a tray in the dental arch without the manipulation of anaesthesia would be an impossible task to accomplish. However, with the administration of chemical compounds by gavage, the objective of the study is maintained, since these compounds are placed in the desired location.

The induction of non-tumour gastric damage is widely performed in several studies with experimental models, such as the use of intragastric indomethacin ${ }^{30}$, cold stress method ${ }^{4}$, the induction by Helicobacter pylori infection, and the administration of iodoacetamide ${ }^{15}$ or ethanol. The experimental model of ethanol can have some variables, but, in this study, it was chosen the administration of $50 \%$ ethanol in $1 \mathrm{ml}$ single dose by gavage, keeping the drinking water with $5 \%$ ethanol for 6 days s $^{2,3,15}$. This experimental model is effective; it is coordinated by the administration of the bleaching product and avoids the recovery of the induced lesions in the mucosa, which occurs in single-dose models ${ }^{29,30}$.

The use of $6 \%$ hydrogen peroxide in this study required the analysis of the probable dose administration with the balance of several factors, contributing to this issue. Some authors reported that during an hour of use of a tray with whitening product, about $50 \%$ of the product escaped from the tray. Part of this can be swallowed with the risk of subsequent adverse effects ${ }^{5}$. Moreover, another factor to take into account is the presence of carbopol in these products of. This substance prolongs the time release of oxygen peroxide, thereby contributing to higher levels of toxicity $5,8,12,19,29$. These two factors are critical to 
determine the dose to be administered to animals.

As mentioned above, the experimental design of the study should be the best mimic for the clinical use of the product. In this case, the manufacturer indicates 1 hour of use twice a day for 30 minutes in a treatment of 3 to 7 days (Colgate ${ }^{\circledR}$ Visible White $^{\mathrm{TM}}$ - Colgate Oral Pharmaceuticals Inc, New York, USA).

The determination of the dose administered to the animals as well as the time of study was based on the clinical protocol recommended by the manufacturer and in several experimental and clinical studies on therapeutic bleaching. Most of these clinical studies concluded that the treatment with carbamide or hydrogen peroxide, depending on the concentrations ( $10 \%$ to $20 \%$ ) of the active ingredient should be performed from 15 to 30 days, according to the type of stains. In vivo animal experimental studies are scarce, and, generally, call for proposals of single daily doses or manipulations of 1 week. Regarding the administered dose, $1 \mathrm{~g} /$ $\mathrm{kg}$ body weight was chosen, since studies suggest that this is closest to the clinical dose. Moreover, this dose is in accordance with the requirements of outpatient therapy for the same type of product made by some authors ${ }^{1,4,5,16,26}$.

During the experimental study, drinking water was not restricted to the animals manipulated with hydrogen peroxide, but their diet was restricted for 3 hours after the administration of the product. According to some studies, the diet should be restricted during the first 3 hours after the administration of the bleaching product, so that it is not diluted by food, diminishing its action ${ }^{1,4,5}$. Other authors state that this restriction should be maintained for four hours 5 .

The statistical analysis of the data on the increase in animal weight throughout the study indicates that there is a decrease in weight gain in all manipulated experimental groups when compared with the weight increase of the control group. In spite of remaining constant, such increase is slight in all groups, except in groups IV and VB. In these groups, weight loss occurs after the administration of ethanol $50 \%$, indicating transient systemic toxicity. On the other hand, the administration of hydrogen peroxide does not induce weight loss, but marked decrease in weight gain. These data reveal the presence of systemic toxicity less severe than that induced by the administration of ethanol.

Regarding the spleen weight of all study groups, there were statistically significant differences detected in the manipulated groups compared with the control group. These are characterized by a decrease in the weight of the body. However, an increase in the weight of the organ would be expected in a situation of systemic toxicity. These differences appear to be negative and also explainable by the decrease in weight gain observed in these animals, thus reducing their body weight in general. The change in spleen weight compared to the weight of the respective animal could be important for the evaluation of the presence of systemic toxicity. Values higher than those from the control group would allow us to consider an increase in spleen weight and, consequently, in the presence of splenomegaly. However, there is only one significant statistical change compared to the control group in the negative direction, indicating a lower spleen weight. However, it seems to be a positive variation in groups III and VB, which may indicate the presence of splenomegaly despite of the fact that such difference is not statistically significant.

The macroscopic analysis of the gastric mucosa was based on various parameters. These parameters were chosen to characterize the type of changes induced by the various chemical compounds used in conjunction with their severity and frequency.

All animal groups showed higher or lower frequency except for the last type of changes that was translated into macroscopically areas corresponding to ulcers. Thus, for the parameters with the presence of macroscopic areas of inflammation, haemorrhage, and erasing of mucosal folds, all groups manipulated had positive frequencies.

These results were expected since substances that may cause lesions to the gastric mucosa were administered in all groups. The parameters corresponding to inflammation and bleeding areas have higher incidence in the groups mentioned, particularly in the groups III and IV. The two groups were manipulated with both types of chemical compounds. Both parameters are more frequent in group IV, with the most relevant one corresponding to macroscopic areas of inflammation and bleeding.

However, in group III, the presence of lesions can be observed in a larger number of animals, despite being less frequent. The bleaching product administered to rats with the presence of non-tumour gastric damage contributes to the maintenance of these same lesions and thus, some favourable clinical evolution may occur. The results suggest an aggravation of gastric lesions caused by the bleaching product in the group IV, when in the presence of $50 \%$ ethanol and drinking water with $5 \%$ ethanol. In the groups II and V, in which it was administered only a single type of chemical compound, such parameters are referred to as positive, but there seems to be a standard set of most common type of lesions. Corroborating these results, the presence of ulcers is also more frequent in the groups III and IV.

The combination of these two chemicals appears to have a synergy, enhancing the appearance of 
lesions and keeping it active, despite being less evident when the bleach product is given in the last week of the study. The erasure of the mucosal folds does not seem to be related with any type of pattern, despite being more common in the groups III, IV, and VA. Although this parameter is evident in some animals, it can occur in limited areas of the mucosa and/or in slight anatomical variations.

\section{CONCLUSI ONS}

Both products administered have caused gastric injury, which was already expected to ethanol considering it is an inductor model of gastric injury. The intensity and the severity of these lesions is greater with the simultaneous administration of the products, without having a pattern or differences in the administration order. Thus, further studies are needed to evaluate the impact of some individual variants of the clinical application of the technique such as long therapies and the increase of the dose or of the concentration of bleaching products.

The systemic toxicity seems to be induced either by the bleaching product, hydrogen peroxide $6 \%$ or by $50 \%$ ethanol, but the severity of the systemic toxicity is greater when both are administered. The weight recovery leads to consider that some are subject to a transient toxicity.

Thus, the bleaching therapy that is carried out with this product should be well monitored by a dentist to avoid the excess of product and of applications, with the careful removal of excesses, avoiding its intake. The trays should always be individualized for better containment of the product and the treatment must be made individually in each dental arch.

\section{REFERENCES}

1- Adam-Rodwell G, Kong BM, Bagley DM, Tonucci D, Christina LM. Safety profile of Colgate Platinum Professional Toothwhitening System. Compend Suppl. 1994;17:S622-66.

2- Birdane FM, Cemek M, Birdane YO, Gülçin I, Büyükokuroglu ME. Beneficial effects of Foeniculum vulgare on ethanol-induced acute gastric mucosal injury in rats. World J Gastroenterol. 2007;13(4):607-11.

3- Cantürk NZ, Cantürk Z, Özbilim G, Yenisey C. Protective effect of vitamin $\mathrm{E}$ on gastric mucosal injury in rats with biliary obstruction. Can J Gastroenterol. 2000;14(6):499-503.

4- Cherry DV, Bowers DE Jr, Thomas L, Redmond AF. Acute toxicological effects of ingested tooth whiteners in female rats. J Dent Res. 1993;72:1298-303.

5- Dahl JE, Becher R. Acute toxicity of carbamide peroxide and a commercially available tooth-bleaching agent in rats. J Dent Res. 1995;74:710-4.

6- Dahl JE, Pallesen U. Tooth bleaching - a critical review of the biological aspects. Crit Rev Oral Biol Med. 2003;14:292-304.
7- Demarco FF, Meireles SS, Masotti AS. Over-the-counter whitening agents: a concise review. Braz Oral Res. 2009;23:64-70. 8- Fearon J. Tooth whitening: concepts and controversies. J Ir Dent Assoc. 2007;53:132-40.

9- Gambarini G, Testarelli L, Luca MD, Dolci G. Efficacy and safety assessment of a new liquid tooth whitening gel containing 5.9\% hydrogen peroxide. Am J Dent. 2004;17(2):75-9.

10- Gerlach RW, Barker ML. Randomized clinical trial comparing overnight use of two self-directed peroxide tooth whiteners. Am J Dent. 2003;16:17B-21B.

11- Gökay O, Müjdeci A, Algn E. Peroxide penetration into the pulp from whitening strips. J Endod. 2004;30:887-9.

12- Goldberg M, Grootveld M, Lynch E. Undesirable and adverse effects of tooth-whitening products: a review. Clin Oral Invest. 2010;14:1-10.

13- Haywood VB. New bleaching considerations compared with at-home bleaching. J Esthet Restor Dent. 2003;15:184-7.

14- Haywood VB, Leonard RH, Nelson CF, Brunson WD. Effectiveness, side effects and long-term status of nightguard vital bleaching. J Am Dent Assoc. 1994;125:1219-26.

15- Hernández-Muñoz R, Montiel-Ruíz C, Vázquez-Martínez 0. Gastric mucosal cell proliferation in ethanol-induced chronic mucosal injury is related to oxidative stress and lipid peroxidation in rats. Lab Invest. 2000;80:1161-9.

16- Kelleher MG, Roe FJ. The safety-in-use $10 \%$ carbamide peroxide (Opalescence) for bleaching teeth under the supervision of a dentist. Br Dent J. 1999;187:190-4

17- Kugel G, Kastali S. Tooth-whitening efficacy and safety: a randomized and controlled clinical trial. Compend Contin Educ Dent Suppl. 2000;21:S16-S21.

18- Li Y. Biological properties of peroxide-containing tooth whiteners. Food Chem Toxicol. 1996;34:887-904.

19- Li Y. Toxicological considerations of tooth bleaching using peroxide-containing agents. J Am Dent Assoc. 1997;128:31S-36S. 20- Li Y. The safety of peroxide-containing at-home tooth whiteners. Compend COntin Educ Dent. 2003;4A:384-9.

21- Matis BA, Wang Y, Eckert GJ, Cochran MA, Jiang T. Extended bleaching of tetracicline-stained teeth: a 5-year study. Oper Dent. 2006;31:643-51.

22- Minoux M, Serfaty R. Vital tooth bleaching: biologic adverse effects - a review. Quintessence Int. 2008;39:645-59.

23- Munro IC, Williams GM, Heymann HO, Kroes R. Tooth whitening products and the risk of oral cancer. Food Chem Toxicol. 2006;44:301-15.

24- Niedeman R, Tantrapol MC, Slinin P, Hayes C, Conway S. Effectiveness of dentist-prescribed, home-applied tooth whitening. A meta-analysis. J Contemp Dent Pract. 2000;4:20-36.

25- Pugh G Jr, Zaidel L, Lin N, Stranick M, Bagley D. High levels of hydrogen peroxide in overnight tooth-whitening formulas: effects on enamel and pulp. J Esthet Restor Dent. 2005;17:40-7.

26- Redmond AF, Cherry DV, Bowers DE Jr. Acute illness and recovery in adult female rats following ingestion of a tooth whitener containing 6\% hydrogen peroxide. Am J Dent. 1997;10:268-71. 27- Shethri SA, Matis BA, Cochran MA, Zekonis R, Stropes M. A clinical evaluation of two in-office bleaching products. Oper Dent. 2003;28:488-95.

28- Walsh LJ. Safety issues relating to the use of hydrogen peroxide in dentistry. Aust Dent J. 2000;45:257-69.

29- Weiner ML, Freeman C, Trochimowicz H, de Gerlache J, Jacobi S, Malinverno G, et al. 13-week drinking water toxicity study of hydrogen peroxide with 6-week recovery period in catalasedeficient mice. Food Chem Toxicol. 2000;38:607-15.

30- Xiang Z, Si JM, Huang HD. Chronic gastritis rat model and role of inducing factors. World J Gastroenterol. 2004;10:3212-4. 